\title{
Impact of chronic obstructive pulmonary disease on 10-year mortality after percutaneous coronary intervention and bypass surgery for complex coronary artery disease: insights from the SYNTAX Extended Survival study
}

\author{
Rutao Wang ${ }^{1,2,3} \cdot$ Mariusz Tomaniak $^{4,5} \cdot$ Kuniaki Takahashi $^{6} \cdot$ Chao Gao $^{1,2,3} \cdot$ Hideyuki Kawashima $^{2,6}$. \\ Hironori Hara ${ }^{2,6}$. Masafumi Ono ${ }^{2,6}$. David van Klaveren ${ }^{7,8} \cdot$ Robert-Jan van Geuns $^{3}$ - Marie-Claude Morice ${ }^{9}$ \\ Piroze M. Davierwala ${ }^{10}$. Michael J. Mack ${ }^{11}$. Adam Witkowski ${ }^{12} \cdot$ Nick Curzen $^{13} \cdot$ Sergio Berti $^{14}$. \\ Francesco Burzotta ${ }^{15}$. Stefan James ${ }^{16}$. Arie Pieter Kappetein ${ }^{17}$. Stuart J. Head ${ }^{17}$. Daniel J. F. M. Thuijs ${ }^{17}$. \\ Friedrich W. Mohr ${ }^{10} \cdot$ David R. Holmes $^{18} \cdot$ Ling Tao $^{1} \cdot$ Yoshinobu Onuma ${ }^{2}$ Patrick W. Serruys $s^{2,19,20}$
}

Received: 2 January 2021 / Accepted: 1 March 2021 / Published online: 12 March 2021

(c) The Author(s) 2021

\begin{abstract}
Aims To evaluate the impact of chronic obstructive pulmonary disease (COPD) on 10-year all-cause death and the treatment effect of CABG versus PCI on 10-year all-cause death in patients with three-vessel disease (3VD) and/or left main coronary artery disease (LMCAD) and COPD.

Methods Patients were stratified according to COPD status and compared with regard to clinical outcomes. Ten-year allcause death was examined according to the presence of COPD and the revascularization strategy.

Results COPD status was available for all randomized 1800 patients, of whom, 154 had COPD (8.6\%) at the time of randomization. Regardless of the revascularization strategy, patients with COPD had a higher risk of 10-year all-cause death, compared with those without COPD (43.1\% vs. 24.9\%; hazard ratio [HR]: 2.03; 95\% confidence interval [CI]: 1.56-2.64; $p<0.001)$. Among patients with COPD, CABG appeared to have a slightly lower risk of 10-year all-cause death compared
\end{abstract}

Patrick W. Serruys

patrick.w.j.c.serruys@gmail.com

1 Department of Cardiology, Xijing Hospital, Xi'an, China

2 Department of Cardiology, National University of Ireland, Galway (NUIG), P.O. University Road, Galway H91 TK33, Ireland

3 Department of Cardiology, Radboud University Medical Center, Nijmegen, The Netherlands

4 First Department of Cardiology, Medical University of Warsaw, Warsaw, Poland

5 Department of Cardiology, Erasmus University Medical Center, Rotterdam, The Netherlands

6 Department of Cardiology, Amsterdam Universities Medical Centers, Location Academic Medical Center, University of Amsterdam, Amsterdam, The Netherlands

7 Department of Public Health, Erasmus University Medical Center, Rotterdam, The Netherlands

8 Predictive Analytics and Comparative Effectiveness Center, Institute for Clinical Research and Health Policy Studies, Tufts Medical Center, Boston, USA

9 ICPS Ramsay-Generale de Sante, Massy, France
10 Department of Cardiac Surgery, Heart Centre Leipzig, Leipzig, Germany

11 Baylor Scott \& White Health, Plano, TX, USA

12 Department of Interventional Cardiology and Angiology, National Institute of Cardiology, Warsaw, Poland

13 Cardiology Department, University Hospital Southampton, Southampton, UK

14 Cardiology Department, Heart Hospital-Fondazione C.N.R. Reg. Toscana G. Monasterio, Massa, Italy

15 Institute of Cardiology, Fondazione Policlinico Universitario Agostino Gemelli IRCCS, Università Cattolica del Sacro Cuore, Rome, Italy

16 Department of Medical Sciences and Uppsala Clinical Research Center, Uppsala University, Uppsala, Sweden

17 Department of Cardiothoracic Surgery, Erasmus University Medical Centre, Rotterdam, The Netherlands

18 Mayo Clinic, Rochester, MN, USA

19 NHLI, Imperial College London, London, UK

20 Erasmus University Medical Center, Rotterdam, The Netherlands 
with PCI (42.3\% vs. $43.9 \%$; HR: 0.96; 95\% CI: 0.59-1.56, $p=0.858)$, whereas among those without COPD, CABG had a significantly lower risk of 10 -year all-cause death $(22.7 \%$ vs. $27.1 \%$; HR: $0.81 ; 95 \%$ CI: $0.67-0.99, p=0.041)$. There was no significant differential treatment effect of CABG versus PCI on 10-year all-cause death between patients with and without $\operatorname{COPD}\left(p_{\text {interaction }}=0.544\right)$.

Conclusions COPD was associated with a higher risk of 10 -year all-cause death after revascularization for complex coronary artery disease. The presence of COPD did not significantly modify the beneficial effect of CABG versus PCI on 10-year all-cause death.

Trial registration: SYNTAX: ClinicalTrials.gov reference: NCT00114972. SYNTAX Extended Survival: ClinicalTrials. gov reference: NCT03417050

\section{Graphic abstract}

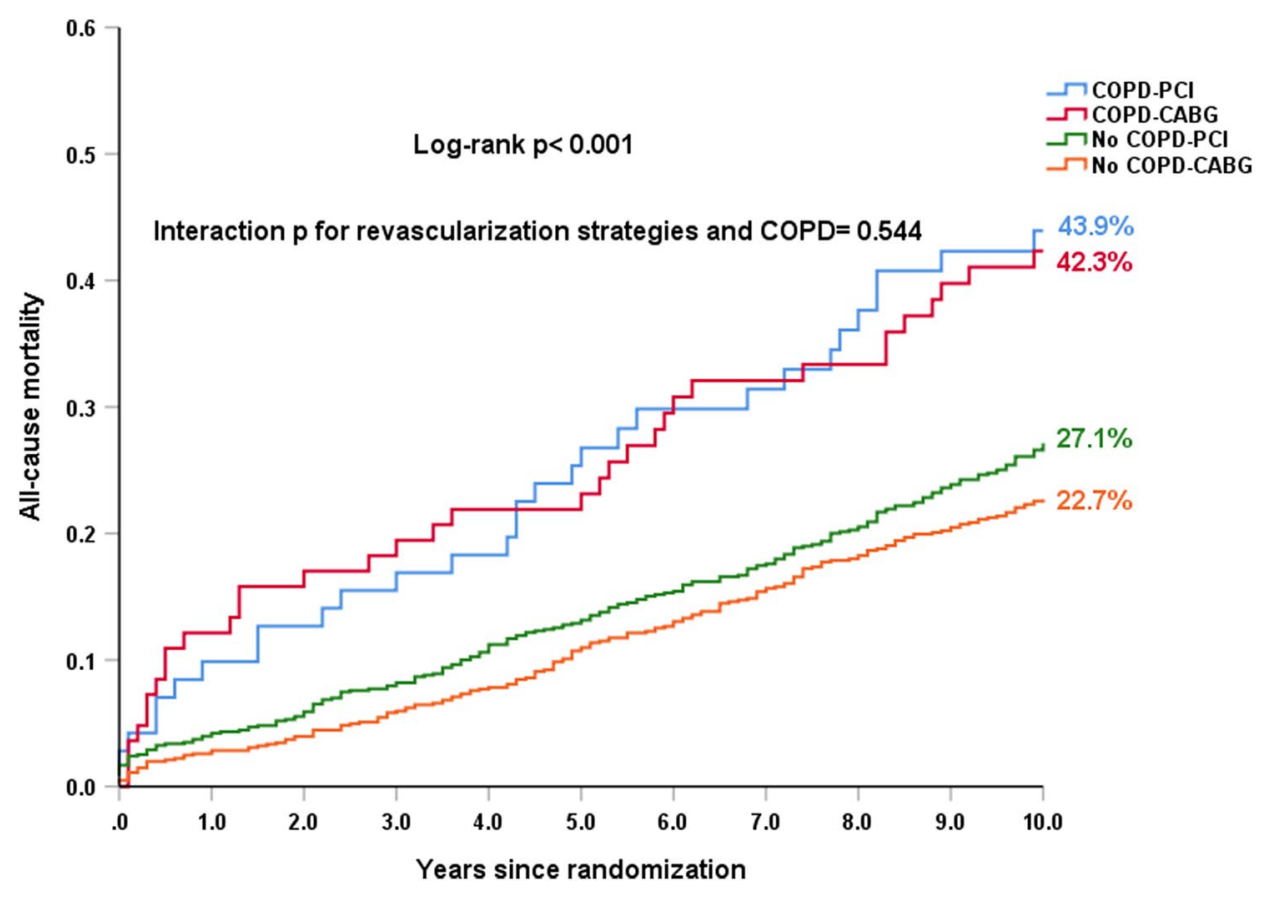

Keywords All-cause death $\cdot$ Chronic obstructive pulmonary disease $\cdot$ Coronary artery bypass grafting $\cdot$ Percutaneous coronary intervention $\cdot$ SYNTAX

\section{Introduction}

Chronic obstructive pulmonary disease (COPD) is associated with accelerated atherosclerosis and cardiovascular disease; therefore, they frequently coexist [1,2]. Known as a risk factor for cardiovascular mortality [3], the status of COPD is a variable in the formula to calculate SYNTAX score II [4-6], Southern Thoracic Society (STS) score [7], EuroSCORE II [8], and more recently-the SYNTAX score II 2020 [9]. Patients with COPD are perceived to be at increased surgical risk, and are often referred to percutaneous coronary intervention (PCI) instead of coronary bypass artery grafting (CABG). However, limited data support this preference. Most studies have indeed demonstrated that COPD patients undergoing CABG had increased in-hospital and long-term mortality [10, 11], whilst some studies reported discrepant results $[12,13]$. On the other hand, patients with COPD who underwent PCI have worse prognosis compared with those without COPD [14-17]. Furthermore, in the EXCEL (Evaluation of XIENCE Versus Coronary Artery Bypass Surgery for Effectiveness of Left Main Revascularization) trial, COPD was associated with worse clinical outcomes after left main coronary artery disease (LMCAD) revascularization. Yet the relative risks of PCI versus CABG at 30 days and 3 years were similar irrespective of the presence of COPD in this specific subset of patients [18]. Currently, therefore, the optimal revascularization strategy for patients with COPD and complex CAD remains debatable.

The SYNTAX Extended Survival (SYNTAXES) study reported the 10 -year all-cause mortality in $94 \%$ of all the 
patients with de novo three-vessel disease (3VD) and/or LMCAD who were originally randomized to CABG or PCI in the SYNTAX trial [19]. In the present study, we aimed 1) to evaluate the impact of COPD on 10-year all-cause mortality and 2) to estimate the treatment effect of CABG versus PCI for 10-year all-cause mortality according to COPD in patients with $3 \mathrm{VD}$ and/or LMCAD.

\section{Methods}

\section{Study design and population}

The design and the primary results of the SYNTAX trial have been published elsewhere [20-22]. In brief, the SYNTAX trial (NCT00114972) was an international, multicenter, randomized controlled trial conducted between March 2005 and April 2007. Based on clinical judgment and the consensus of a Heart Team, all-comers patients with de novo 3VD and/or LMCAD deemed eligible for both PCI and CABG were enrolled and randomized in a 1:1 fashion to either CABG $(n=897)$ or PCI $(n=903)$ with the TAXUS Express paclitaxel-drug eluting stents (Boston Scientific Corporation, Marlborough, MA, USA). The trial completed the patient follow-up to 5 years [22]. The SYNTAXES study (NCT03417050) was an investigator-driven initiative that extended follow-up and aimed to evaluate vital status up to 10 years [19]. The longest follow-up was 14.1 years. The extended follow-up study was funded by the German Heart Research Foundation (GHF; Frankfurt am Main, Germany). Follow-up was conducted in accordance with local regulations of each participating center and complied with the declaration of Helsinki.

\section{Definitions and endpoints}

COPD at baseline was defined as long-term use of bronchodilators or steroids for lung disease according to the definition in EuroSCORE [23]. The primary endpoint of the SYNTAXES study was all-cause death at 10 years. The 30-day and 5-year major adverse cardiovascular and cerebrovascular events (MACCE, defined as a composite endpoint of allcause death, cerebrovascular accident, myocardial infarction $[\mathrm{MI}]$ or repeat revascularization, the primary endpoint of the SYNTAX trial) according to the status of COPD were also explored in the current analysis. Vital status was confirmed by contact with medical care personnel and/or by electronic healthcare record review and national death registry.

\section{Statistical analysis}

All the analyses were performed according to the intention to treat principle. Continuous variables are reported as mean \pm standard deviations, and were compared using Student's $t$ test or Mann-Whitney $U$ test. Categorical variables are shown as percentages and numbers and were compared using Fisher's exact test. Time-to-event Kaplan-Meier estimates with log-rank test were used to compare COPD versus non-COPD in the PCI and CABG arm, respectively, and to compare PCI with CABG according to COPD. Cox proportional hazards regression was used to calculate hazard ratios (HRs) with 95\% confidence interval (CI). Multivariate analysis was performed to investigate whether COPD was an independent predictor of all-cause death at 10 years. The Cox proportional hazards regression model included the following covariates: age, gender, body mass index, current smoking, peripheral vascular disease, left ventricular ejection fraction (LVEF), creatinine clearance $(\mathrm{ml} / \mathrm{min})$, prior MI, prior stroke, and the anatomical SYNTAX score, which have been selected based on previous knowledge of the association of those variables with the clinical outcomes [24]. All analyses were performed using SPSS Statistics, version 25 (IBM Corp., Armonk, 281 N.Y., USA) and a $p$ value of $<0.05$ was considered to be statistically significant.

\section{Results}

\section{Baseline characteristics}

COPD status was available in all patients randomized in the SYNTAX trial. Of the 1800 participants, 154 (8.6\%) had COPD. Baseline characteristics according to COPD status are shown in Table 1. Patients with COPD were more likely to be older, had more cardiovascular risk factors (previous carotid artery disease, peripheral vascular disease, congestive heart failure, and current smoking), and had a higher EuroSCORE and Parsonnet SCORE, as compared to those without COPD. They were less likely to receive arterial conduits and to take aspirin and beta blockers at discharge. Baseline clinical and procedural characteristics according to COPD as well as randomized revascularization strategies are reported in Table 2. By randomization, baseline clinical and procedural characteristics were largely well balanced between PCI and CABG in patients with and without COPD.

\section{Outcomes according to COPD}

When compared to those without COPD, patients with COPD had a comparable MACCE rate at 30 days (5.8\% vs. $5.2 \%$, HR: $1.12,95 \%$ CI: $0.57-2.24, p=0.738)$, but had a higher 5-year MACCE rate (41.4\% vs. $32.1 \%$, HR: 1.42 , 95\% CI: $1.09-1.85, p=0.010$ ), which was mainly driven by a higher 5 -year all-cause death (23.2\% vs. $12.2 \%$, HR: 2.15 , 95\% CI: $1.49-3.10, p<0.001$ ) (Table 3). A significantly higher risk of all-cause death at 10 years was observed 
Table 1 Baseline characteristics according to COPD

\begin{tabular}{|c|c|c|c|}
\hline & $\operatorname{COPD}(n=154)$ & No $\operatorname{COPD}(n=1646)$ & $p$ value \\
\hline PCI & $46.1(71 / 154)$ & $50.5(832 / 1646)$ & 0.292 \\
\hline CABG & $53.9(83 / 154)$ & $49.5(814 / 1646)$ & \\
\hline Age (year) & $66.9 \pm 8.7$ & $64.9 \pm 9.8$ & 0.017 \\
\hline \multicolumn{4}{|l|}{ Sex } \\
\hline Male & $73.4(113 / 154)$ & $78.1(1285 / 1646)$ & 0.181 \\
\hline Body mass index $\left(\mathrm{kg} / \mathrm{m}^{2}\right)$ & $28.6 \pm 5.6$ & $28.0 \pm 4.6$ & 0.164 \\
\hline Medically treated diabetes & $29.2(45 / 154)$ & $24.7(407 / 1646)$ & 0.219 \\
\hline On insulin & $13(20 / 154)$ & $9.8(162 / 1646)$ & 0.216 \\
\hline Metabolic syndrome & $40.3(62 / 154)$ & $36.1(594 / 1646)$ & 0.352 \\
\hline Hypertension & $71.4(110 / 154)$ & $66(1086 / 1646)$ & 0.171 \\
\hline Dyslipidemia & $77.8(119 / 153)$ & $77.9(1272 / 1632)$ & 0.963 \\
\hline Current smoker & $27.9(43 / 154)$ & $19.5(320 / 1639)$ & 0.013 \\
\hline Previous MI & $36(54 / 150)$ & $32.6(531 / 1630)$ & 0.393 \\
\hline Previous stroke & $5.3(8 / 150)$ & $4.3(70 / 1639)$ & 0.542 \\
\hline Previous TIA & $7.3(11 / 151)$ & $4.5(73 / 1638)$ & 0.116 \\
\hline Previous carotid artery disease & $16.2(25 / 154)$ & $7.5(123 / 1646)$ & $<0.001$ \\
\hline PVD & $19.5(30 / 154)$ & $8.9(147 / 1646)$ & $<0.001$ \\
\hline Impaired renal function & $22.1(34 / 154)$ & $17.1(282 / 1646)$ & 0.155 \\
\hline Creatinine clearance $(\mathrm{ml} / \mathrm{min})$ & $84.8 \pm 32.9$ & $86.2 \pm 32.7$ & 0.630 \\
\hline $\operatorname{LVEF}(\%)$ & $56.9 \pm 14.2$ & $58.8 \pm 12.9$ & 0.171 \\
\hline Congestive heart failure & $8.5(13 / 153)$ & $4.3(70 / 1625)$ & 0.019 \\
\hline \multicolumn{3}{|l|}{ Clinical presentation } & 0.432 \\
\hline Silent ischemia & $14.9(23 / 154)$ & $14.4(237 / 1646)$ & \\
\hline Stable angina & $61(94 / 154)$ & $56.7(933 / 1646)$ & \\
\hline Unstable angina & $24(37 / 154)$ & $28.9(476 / 1646)$ & \\
\hline Euro SCORE & $5.2 \pm 2.9$ & $3.6 \pm 2.6$ & $<0.001$ \\
\hline Parsonnet SCORE & $9.9 \pm 6.9$ & $8.4 \pm 6.9$ & 0.008 \\
\hline \multicolumn{3}{|l|}{ Disease extent } & 0.956 \\
\hline $3 \mathrm{VD}$ & $60.8(1001 / 1646)$ & $61(94 / 154)$ & \\
\hline LMCAD & $39(60 / 154)$ & $39.2(645 / 1646)$ & \\
\hline \multicolumn{3}{|l|}{ Disease extent } & 0.806 \\
\hline LMCAD only & $6.5(10 / 153)$ & $4.9(81 / 1646)$ & \\
\hline $\mathrm{LMCAD}+1 \mathrm{VD}$ & $7.8(12 / 153)$ & $7.7(126 / 1646)$ & \\
\hline $\mathrm{LMCAD}+2 \mathrm{VD}$ & $13.7(21 / 153)$ & $12(1646 / 241)$ & \\
\hline $\mathrm{LMCAD}+3 \mathrm{VD}$ & $11.1(17 / 153)$ & $14.6(241 / 1646)$ & \\
\hline $2 \mathrm{VD}$ & $2(3 / 153)$ & $2(33 / 1646)$ & \\
\hline $3 \mathrm{VD}$ & $58.8(90 / 153)$ & $58.8(968 / 1646)$ & \\
\hline Anatomical SYNTAX score & $29.6 \pm 11.8$ & $28.7 \pm 11.4$ & 0.344 \\
\hline Number of lesions & $4.5 \pm 1.9$ & $4.3 \pm 1.8$ & 0.461 \\
\hline Any total occlusion & $18.3(28 / 153)$ & $23.7(387 / 1634)$ & 0.132 \\
\hline Any bifurcation & $76.5(117 / 153)$ & $72.4(1183 / 1634)$ & 0.279 \\
\hline Number of stents & $4.6 \pm 2.6$ & $4.6 \pm 2.2$ & 0.924 \\
\hline TSL per patient & $85.5 \pm 52.9$ & $85.7 \pm 47.5$ & 0.980 \\
\hline Off pump CABG & $4.5(7 / 154)$ & $7.5(123 / 1646)$ & 0.215 \\
\hline LIMA use & $44.2(68 / 154)$ & $41.1(676 / 1646)$ & 0.757 \\
\hline Number of total conduits & $2.7 \pm 0.8$ & $2.8 \pm 0.7$ & 0.754 \\
\hline Number of arterial conduits & $1.2 \pm 0.5$ & $1.4 \pm 0.7$ & 0.001 \\
\hline Number of venous conduits & $1.5 \pm 0.9$ & $1.3 \pm 0.9$ & 0.103 \\
\hline Complete revascularization & $61.6(93 / 151)$ & $59.8(965 / 1615)$ & 0.660 \\
\hline \multicolumn{4}{|l|}{ Medication at discharge } \\
\hline Aspirin & $87.4(132 / 151)$ & $92.9(1501 / 1615)$ & 0.014 \\
\hline
\end{tabular}


Table 1 (continued)

\begin{tabular}{lllr}
\hline & COPD $(n=154)$ & No COPD $(n=1646)$ & $p$ value \\
\hline Thienopyridine & $53.6(81 / 151)$ & $59.2(956 / 1615)$ & 0.185 \\
Statin & $78.8(119 / 151)$ & $80.9(1306 / 1615)$ & 0.540 \\
Beta blockers & $60.3(91 / 151)$ & $81.8(1321 / 1615)$ & $<0.001$ \\
ACEI & $47.7(72 / 151)$ & $50.2(810 / 1615)$ & 0.561 \\
ARB & $14.6(22 / 151)$ & $9.8(158 / 1615)$ & 0.063 \\
\hline
\end{tabular}

$A C E I$ angiotensin-converting enzyme inhibitors, $A R B$ angiotensin II receptor blockers, $C A B G$ coronary bypass artery grafting, $L M C A D$ left main coronary artery disease, $L V E F$ left ventricular ejection fraction, $M I$ myocardial infarction, $P C I$ percutaneous coronary intervention, $P V D$ peripheral vascular disease, TIA transient ischemia attack, $T S L$ total stent length, $3 V D$ three-vessel disease

in the patients with COPD, compared with those without COPD (43.1\% vs. $24.9 \%$; HR: 2.03 ; $95 \%$ CI: $1.56-2.64$; $p<0.001$, Fig. 1a, Table 3). COPD was associated with a higher 10-year all-cause death in both PCI and CABG arms (Fig. 1b, c).

\section{Clinical outcomes according to revascularization strategy}

There were 71 and 83 COPD patients randomized to PCI and $\mathrm{CABG}$, respectively. Among these patients, differences between CABG and PCI for 30-day MACCE (4.8\% vs. $7.0 \%$, HR: $0.66,95 \%$ CI: $0.18-2.46, p=0.538)$ and 5-year MACCE (35.9\% vs. $47.3 \%$, HR: $0.73,95 \%$ CI: $0.44-1.2, p=0.213$ ) were not statistically significant (Table 4). At 10 years, CABG appeared to have a slightly lower risk of all-cause death compared with PCI (42.3\% vs. $43.9 \%$; HR: $0.96,95 \%$ CI: $0.59-1.56, p=0.858$, Fig. 2a, Table 4) in patients with COPD. By contrast, among those without COPD, CABG had a significantly lower risk of 10-year all-cause death (22.7\% vs. $27.1 \%$; HR: $0.81,95 \%$ CI: $0.67-0.99, p=0.041$, Fig. 2b, Table 4). There was no significant differential treatment effect of CABG versus PCI on the 10-year all-cause death for patients without COPD and patients with COPD $\left(p_{\text {interaction }}=0.544\right.$, Table 4$)$.

\section{Multivariable analysis}

After adjustment for the baseline confounders, COPD remained an independent predictor of all-cause death at 10 years in the CABG arm (adjusted HR: 2.10 , 95\% CI: $1.19-3.69, p=0.010$ ), but was not an independent predictor in the PCI arm (adjusted HR: 1.19, 95\% CI: 0.69-2.06, $p=0.536$ ) (Table 5).

\section{Discussion}

To our knowledge, our study is the first analysis to evaluate the treatment effect of CABG versus PCI on 10-year allcause mortality according to COPD in patients with $3 \mathrm{VD}$ and/or LMCAD. The main findings of the present study are summarized as follows:

(1) No significant difference was found between COPD and non-COPD patients for 30-day MACCE. However, COPD was associated with a significantly increased risk of 5-year and 10-year all-cause death.

(2) The relative treatment effects of CABG versus PCI on 10 -year all-cause death were not significantly different for patients with COPD and patients without COPD.

(3) COPD was an independent predictor of 10-year allcause death after CABG but not after PCI.

\section{The impact of COPD on mortality after revascularization}

COPD has been identified as a risk factor for worse clinical outcomes in CAD patients [3, 25]. However, the literature is inconsistent regarding the impact of COPD on mortality after revascularization. Angouras et al. found that COPD was not an independent predictor of increased early mortality, but was a continuing detrimental risk factor for longterm survival (mean follow-up, 7.6 years) in patients who underwent isolated CABG [26]. Analysis from SWEDEHEART registry demonstrated that patients with COPD had a significantly higher rate of both 30-day and 5-year mortality after CABG [15]. In patients who underwent PCI, previous reports showed discrepant results regarding the impact of COPD on short-term outcomes. Selvaraj et al. found that COPD was a significant independent predictor of in-hospital death and long-term mortality after PCI [16], while Berger et al. reported that in-hospital major adverse cardiac outcomes were not different between COPD and non-COPD groups. However, at 3-year follow-up, mortality for patients with COPD was significantly higher compared to those without COPD ( $21 \%$ vs. $9 \%, p<0.001)$. The investigators found that COPD was independently associated with a twofold increase in the hazard of long-term mortality [27]. In our analysis, we observed that at 30 days patients with COPD had a comparable MACCE rate and a trend for a higher allcause death (3.3\% vs. $1.2 \%$, HR: $2.66,95 \%$ CI: $1.00-7.09$, 
Table 2 Baseline characteristics according to COPD and revascularization strategies

\begin{tabular}{|c|c|c|c|c|c|c|}
\hline & \multicolumn{2}{|c|}{$\operatorname{COPD}(N=154)$} & \multirow[t]{2}{*}{$p$ value } & \multicolumn{2}{|c|}{ No COPD $(N=1646)$} & \multirow[t]{2}{*}{$p$ value } \\
\hline & PCI $(N=71)$ & CABG $(N=83)$ & & PCI $(N=832)$ & CABG $(N=814)$ & \\
\hline Age (year) & $66.8 \pm 8.9$ & $67 \pm 8.5$ & 0.916 & $65.1 \pm 9.7$ & $64.8 \pm 9.9$ & 0.476 \\
\hline \multicolumn{7}{|l|}{ Sex } \\
\hline Male & $71.8(51 / 71)$ & $74.7(62 / 83)$ & 0.688 & $76.8(639 / 832)$ & $79.4(646 / 814)$ & 0.210 \\
\hline Body mass index $\left(\mathrm{kg} / \mathrm{m}^{2}\right)$ & $29.3 \pm 5.5$ & $28 \pm 5.6$ & 0.147 & $28 \pm 4.7$ & $27.9 \pm 4.4$ & 0.648 \\
\hline Medically treated diabetes & $33.8(24 / 71)$ & $25.3(21 / 83)$ & 0.248 & $24.9(207 / 832)$ & $24.6(200 / 814)$ & 0.884 \\
\hline On insulin & $14.1(10 / 71)$ & $12(10 / 83)$ & 0.708 & $9.5(79 / 832)$ & $10.2(83 / 814)$ & 0.633 \\
\hline Metabolic syndrome & $46.5(33 / 71)$ & $34.9(29 / 83)$ & 0.032 & $36.8(306 / 832)$ & $35.4(288 / 814)$ & 0.380 \\
\hline Hypertension & $74.6(53 / 71)$ & $68.7(57 / 83)$ & 0.413 & $68.4(569 / 832)$ & $63.5(517 / 814)$ & 0.037 \\
\hline Dyslipidemia & $76.1(54 / 71)$ & $79.3(65 / 82)$ & 0.634 & $78.9(651 / 825)$ & $77(621 / 807)$ & 0.340 \\
\hline Current smoker & $25.4(18 / 71)$ & $30.1(25 / 83)$ & 0.511 & $17.9(149 / 832)$ & $21.2(171 / 807)$ & 0.094 \\
\hline Previous MI & $33.3(23 / 69)$ & $38.3(31 / 81)$ & 0.530 & $31.8(262 / 824)$ & $33.4(269 / 806)$ & 0.497 \\
\hline Previous stroke & $7.2(5 / 69)$ & $3.7(3 / 81)$ & 0.336 & $3.6(30 / 830)$ & $4.9(40 / 809)$ & 0.183 \\
\hline Previous TIA & $10(7 / 70)$ & $4.9(4 / 81)$ & 0.233 & $3.9(32 / 831)$ & $5.1(41 / 807)$ & 0.228 \\
\hline Previous carotid artery disease & $19.7(14 / 71)$ & $13.3(11 / 83)$ & 0.278 & $7.1(59 / 832)$ & $7.9(64 / 814)$ & 0.552 \\
\hline PVD & $21.1(15 / 71)$ & $18.1(15 / 83)$ & 0.633 & $8.1(67 / 832)$ & $9.8(80 / 814)$ & 0.207 \\
\hline Impaired renal function & $23.9(17 / 71)$ & $20.5(17 / 83)$ & 0.139 & $18(150 / 832)$ & $16.2(132 / 814)$ & $<0.001$ \\
\hline Creatinine clearance (ml/min) & $86.2 \pm 34.7$ & $83.6 \pm 31.3$ & 0.650 & $86.7 \pm 35.6$ & $85.7 \pm 29.3$ & 0.565 \\
\hline LVEF $(\%)$ & $58.2 \pm 12.3$ & $55.6 \pm 15.9$ & 0.363 & $59.1 \pm 13$ & $58.5 \pm 12.9$ & 0.453 \\
\hline Congestive heart failure & $4.2(3 / 71)$ & $12.2(10 / 82)$ & 0.078 & $4(33 / 827)$ & $4.6(37 / 798)$ & 0.521 \\
\hline Clinical presentation & & & 0.138 & & & 0.998 \\
\hline Silent ischemia & $9.9(7 / 71)$ & $19.3(16 / 83)$ & & $14.4(120 / 832)$ & $14.4(117 / 814)$ & \\
\hline Stable angina & $60.6(43 / 71)$ & $61.4(51 / 83)$ & & $56.6(471 / 832)$ & $56.8(462 / 814)$ & \\
\hline Unstable angina & $29.6(21 / 71)$ & $19.3(16 / 83)$ & & $29(241 / 832)$ & $28.9(235 / 814)$ & \\
\hline Euro SCORE & $5.4 \pm 3$ & $5.1 \pm 2.7$ & 0.636 & $3.6 \pm 2.5$ & $3.6 \pm 2.7$ & 0.802 \\
\hline Parsonnet SCORE & $10.5 \pm 7.4$ & $9.4 \pm 6.5$ & 0.343 & $8.4 \pm 6.9$ & $8.3 \pm 6.9$ & 0.924 \\
\hline Disease extent & & & 0.657 & & & 0.842 \\
\hline $3 \mathrm{VD}$ & $59.2(42 / 71)$ & $62.7(52 / 83)$ & & $60.6(504 / 832)$ & $61.1(497 / 814)$ & \\
\hline LMCAD & $40.8(29 / 71)$ & $37.3(31 / 83)$ & & $39.4(328 / 832)$ & $38.9(317 / 814)$ & \\
\hline Disease extent & & & 0.983 & & & 0.915 \\
\hline LMCAD only & $7(5 / 71)$ & $6.1(5 / 82)$ & & $4.4(37 / 832)$ & $5.4(44 / 814)$ & \\
\hline $\mathrm{LMCAD}+1 \mathrm{VD}$ & $7(5 / 71)$ & $8.5(7 / 82)$ & & $7.5(62 / 832)$ & $7.9(64 / 814)$ & \\
\hline $\mathrm{LMCAD}+2 \mathrm{VD}$ & $14.1(71 / 9)$ & $13.4(11 / 82)$ & & $12.3(832 / 127)$ & $11.7(95 / 814)$ & \\
\hline $\mathrm{LMCAD}+3 \mathrm{VD}$ & $12.7(9 / 71)$ & $9.8(8 / 82)$ & & $15.3(127 / 832)$ & $14(114 / 814)$ & \\
\hline $2 \mathrm{VD}$ & $1.4(1 / 71)$ & $2.4(2 / 82)$ & & $1.9(16 / 832)$ & $2.1(17 / 814)$ & \\
\hline $3 \mathrm{VD}$ & $57.7(41 / 71)$ & $59.8(49 / 82)$ & & $58.7(488 / 832)$ & $59(480 / 814)$ & \\
\hline Anatomical SYNTAX score & $30 \pm 12.6$ & $29.2 \pm 11.1$ & 0.666 & $28.3 \pm 11.4$ & $29.1 \pm 11.4$ & 0.149 \\
\hline Number of lesions & $4.5 \pm 2$ & $4.4 \pm 1.8$ & 0.643 & $4.3 \pm 1.8$ & $4.4 \pm 1.8$ & 0.426 \\
\hline Any total occlusion & $25.4(18 / 71)$ & $12.2(10 / 82)$ & 0.036 & $24.1(199 / 826)$ & $23.3(188 / 808)$ & 0.695 \\
\hline Any bifurcation & $74.6(53 / 71)$ & $78(64 / 82)$ & 0.621 & $72.2(596 / 826)$ & $72.6(587 / 808)$ & 0.823 \\
\hline Number of stents & $4.7 \pm 2.6$ & - & & $4.6 \pm 2.2$ & - & \\
\hline TSL per patient & $86.6 \pm 53.2$ & - & & $86.4 \pm 47.5$ & - & \\
\hline Off pump CABG & - & $8.4(7 / 83)$ & & - & $14.9(121 / 814)$ & \\
\hline LIMA use & - & $81.9(68 / 83)$ & & - & $81.8(666 / 814)$ & \\
\hline Number of total conduits & - & $2.7 \pm 0.8$ & & - & - & 0.300 \\
\hline Number of arterial conduits & - & $1.2 \pm 0.5$ & & - & - & 0.005 \\
\hline Number of venous conduits & - & $1.5 \pm 0.9$ & & - & - & 0.700 \\
\hline Complete revascularization & $53.5(38 / 71)$ & $68.8(55 / 80)$ & 0.055 & $57(470 / 825)$ & $62.7(495 / 790)$ & 0.020 \\
\hline Medication at discharge & & & & & & \\
\hline
\end{tabular}


Table 2 (continued)

\begin{tabular}{|c|c|c|c|c|c|c|}
\hline & \multicolumn{2}{|c|}{$\operatorname{COPD}(N=154)$} & \multirow[t]{2}{*}{$p$ value } & \multicolumn{2}{|c|}{ No COPD $(N=1646)$} & \multirow[t]{2}{*}{$p$ value } \\
\hline & PCI $(N=71)$ & $\operatorname{CABG}(N=83)$ & & PCI $(N=832)$ & $\operatorname{CABG}(N=814)$ & \\
\hline Aspirin & $93(66 / 71)$ & $82.5(66 / 80)$ & 0.053 & $96.6(797 / 825)$ & $89.1(704 / 790)$ & $<0.001$ \\
\hline Thienopyridine & $94.4(67 / 71)$ & $17.5(14 / 80)$ & $<0.001$ & $97(800 / 825)$ & $19.7(156 / 790)$ & $<0.001$ \\
\hline Statin & $84.5(60 / 71)$ & $73.8(59 / 80)$ & 0.106 & $86.9(717 / 825)$ & $74.6(589 / 790)$ & $<0.001$ \\
\hline Beta blockers & $56.3(40 / 71)$ & $63.8(51 / 80)$ & 0.353 & $83.4(688 / 825)$ & $80.1(633 / 790)$ & 0.089 \\
\hline ACEI & $49.3(35 / 71)$ & $46.3(37 / 80)$ & 0.708 & $55.6(459 / 825)$ & $44.4(351 / 790)$ & $<0.001$ \\
\hline ARB & $21.1(15 / 71)$ & $8.8(7 / 80)$ & 0.031 & $12.6(104 / 825)$ & $6.8(54 / 790)$ & $<0.001$ \\
\hline
\end{tabular}

$A C E I$ angiotensin-converting enzyme inhibitors, $A R B$ angiotensin II receptor blockers, $C A B G$ coronary bypass artery grafting, $L M C A D$ left main coronary artery disease, $L V E F$ left ventricular ejection fraction, $M I$ myocardial infarction, $P C I$ percutaneous coronary intervention, $P V D$ peripheral vascular disease, TIA transient ischemia attack, TSL total stent length, $3 V D$ three-vessel disease

Table 3 Risk of COPD on outcomes according to treatment strategies

\begin{tabular}{llllr}
\hline & $\begin{array}{l}\text { COPD } \\
(n=154)\end{array}$ & $\begin{array}{l}\text { No COPD } \\
(n=1646)\end{array}$ & Unadjusted HR (95\% CI $)$ & $p$ value \\
\hline At 30 days & & & & \\
MACCE & $5.8(9)$ & $5.2(85)$ & $1.12(0.57-2.24)$ & 0.738 \\
Death, stroke, MI & $5.8(9)$ & $4.1(67)$ & $1.43(0.71-2.87)$ & 0.311 \\
All-cause death & $3.3(5)$ & $1.2(20)$ & $2.66(1.00-7.09)$ & 0.050 \\
Cardiac death & $3.3(5)$ & $1.2(20)$ & $2.66(1.00-7.09)$ & 0.050 \\
Any MI & $4.6(7)$ & $2.9(48)$ & $1.56(0.71-3.45)$ & 0.272 \\
Any stroke & $0(0)$ & $0.7(12)$ & $0.04(0-314.05)$ & 0.489 \\
Any repeat revascularization & $2.0(3)$ & $2.3(37)$ & $0.86(0.27-2.8)$ & 0.806 \\
At 5 years & & & & 0.010 \\
MACCE & $41.4(61)$ & $32.1(500)$ & $1.42(1.09-1.85)$ & $<0.001$ \\
Death, stroke, MI & $29.9(44)$ & $18.3(284)$ & $1.81(1.32-2.49)$ & $<0.001$ \\
All-cause death & $23.2(34)$ & $12.2(186)$ & $2.15(1.49-3.10)$ & 0.001 \\
Cardiac death & $13.8(20)$ & $6.7(102)$ & $2.27(1.41-3.67)$ & 0.119 \\
Any MI & $10.0(14)$ & $6.6(102)$ & $1.56(0.89-2.73)$ & 0.329 \\
Any stroke & $4.4(6)$ & $2.9(45)$ & $1.53(0.65-3.58)$ & 0.583 \\
Any repeat revascularization & $22.1(29)$ & $20.2(303)$ & $1.11(0.76-1.63)$ & $<0.001$ \\
At 10 years & & & & $2.03(1.56-2.64)$ \\
All-cause death & $43.1(64)$ & $24.9(396)$ & \\
\hline
\end{tabular}

$C O P D$ chronic obstructive pulmonary disease, $M I$ myocardial infarction, $M A C C E$ major adverse cardiovascular and cerebrovascular event. Data are presented as percentage based on Kaplan-Meier estimates (number of deaths) $p=0.050$, Table 3). In terms of long-term survival, we found that COPD was associated with a significantly increased risk of 5-year and 10-year all-cause mortality both in the CABG arm and in the PCI arm. Our findings are consistent with previous studies reporting COPD is associated with a high risk of long-term mortality after revascularization [26, 27].

The explanations for these inconsistent results with respect to short-term mortality may be multifactorial. Varied definitions for COPD and different enrolled populations in these studies may partly contribute to the inconsistency. In addition, some studies have demonstrated that operative mortality after CABG is associated with the severity of
COPD. A smaller study that evaluated the impact of COPD on $\mathrm{CABG}$ outcome found that only severe COPD influenced hospital deaths, so that hospital mortality in patients with mild-to-moderate COPD undergoing CABG was similar to those without COPD [28]. Subsequently, Fuster et al. found that in-hospital mortality was directly related to the severity of lung disease. Specifically, patients with forced expiratory volume in the first second (FEV 1$)<60 \%$ predicted had higher mortality than those with FEV $1>60 \%$, and that this should be considered as a primary prognostic factor in COPD patients undergoing CABG procedures [29]. Moreover, restrictive lung disease may carry a greater prognostic 

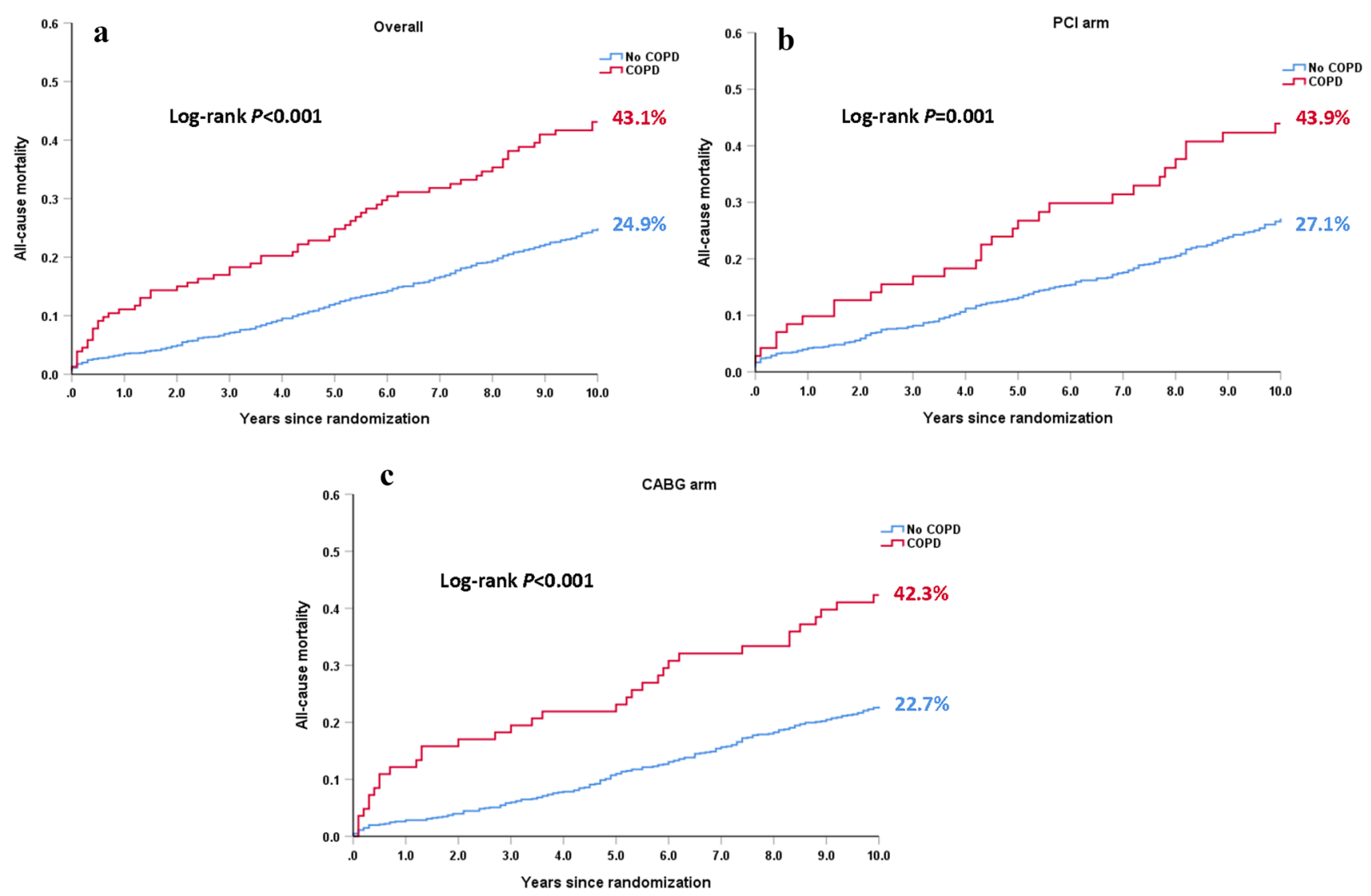

Fig. 1 Kaplan-Meier curves for all-cause death at 10 years in patients with (red) or without (blue) COPD among the overall cohort, the PCI arm and the CABG arm. a 10-year all-cause mortality according to COPD in the overall cohort. b 10 -year all-cause mortality according

impact than obstructive [11]. However, there are again inconsistent data. Michalopoulos et al. reported that patients with a history of mild or moderate COPD undergoing elective $\mathrm{CABG}$ had morbidity and mortality rates comparable to those without COPD [30]. Manganas et al. reported that the mortality rate associated with CABG is not affected by the presence and severity of airflow obstruction in patients with COPD, although the incidence of pulmonary infections and length of hospital stay were increased in patients with severe COPD [12]. Further studies are required to determine the impact of COPD on short-term outcomes.

\section{Is there an optimal revascularization strategy for patients with COPD?}

To date, limited data exist in terms of the optimal revascularization strategy for patients with COPD and complex CAD. To our knowledge, our study is the first analysis to evaluate the treatment effect of CABG versus PCI on 10-year all-cause mortality according to COPD in patients with $3 \mathrm{VD}$ and/or LMCAD. In the EXCEL trial, patients with COPD to COPD in the PCI arm. c 10-year all-cause mortality according to COPD in the CABG arm. Event rates represent Kaplan-Meier estimates

had a trend for a higher all-cause death at 30 days (3.0\% vs. $0.9 \%, p=0.06$ ) compared to those without COPD [18], which is similar to our findings. With regard to long-term outcomes, a higher 3-year mortality was observed in patients with COPD. Furthermore, in the EXCEL trial there were no statistically significant interactions in the relative risks of PCI versus CABG for the primary composite endpoint (death, stroke, MI or ischemia-driven revascularization) in patients with and without COPD at 3 years [18]. These findings are consistent with our current analysis, in which COPD was associated with a higher 10-year all-cause death, and no significant interaction between COPD and treatment strategy (CABG versus PCI) was found for all-cause death at 10 years. Although patients with COPD represent an increased surgical risk, patients with severe COPD have an acceptable long-term survival [11] compared to PCI and should therefore not be routinely denied CABG. More importantly, LIMA utilization in patients with COPD results in a significantly increased long-term survival, without an increased intensive care unit stay, re-intubation rate or inhospital mortality rate [11]. Moreover, Ovaliet et al. found 
Table 4 Treatment effect on outcomes in COPD and non-COPD patients

\begin{tabular}{|c|c|c|c|c|c|c|c|c|c|}
\hline & \multicolumn{3}{|c|}{$\operatorname{COPD}(N=154)$} & \multirow[t]{2}{*}{$p$ value } & \multicolumn{3}{|c|}{ No COPD $(N=1646)$} & \multirow[t]{2}{*}{$p$ value } & \multirow[t]{2}{*}{$p$ interaction } \\
\hline & $\begin{array}{l}\text { CABG } \\
(N=83)\end{array}$ & $\mathrm{PCI}(N=71)$ & HR $(95 \%$ CI $)$ & & $\begin{array}{l}\text { CABG } \\
(N=814)\end{array}$ & PCI $(N=832)$ & HR $(95 \%$ CI $)$ & & \\
\hline \multicolumn{10}{|l|}{ At 30 days } \\
\hline MACCE & $4.8(4)$ & $7.0(5)$ & $\begin{array}{l}0.66(0.18- \\
2.46)\end{array}$ & 0.538 & $4.6(37)$ & $5.8(48)$ & $\begin{array}{l}0.79(0.51- \\
1.21)\end{array}$ & 0.282 & 0.798 \\
\hline $\begin{array}{l}\text { All-cause } \\
\text { death, } \\
\text { stroke, MI }\end{array}$ & $4.8(4)$ & $7.0(5)$ & $\begin{array}{l}0.66(0.18- \\
2.46)\end{array}$ & 0.538 & $3.7(30)$ & $4.5(37)$ & $\begin{array}{c}0.83(0.52- \\
1.35)\end{array}$ & 0.460 & 0.745 \\
\hline $\begin{array}{l}\text { All-cause } \\
\text { death }\end{array}$ & $2.4(2)$ & $4.2(3)$ & $\begin{array}{l}0.56(0.09- \\
3.34)\end{array}$ & 0.523 & $0.5(4)$ & $1.9(16)$ & $\begin{array}{l}0.26(0.09- \\
0.77)\end{array}$ & 0.015 & 0.466 \\
\hline Cardiac death & $2.4(2)$ & $4.2(3)$ & $\begin{array}{l}0.56(0.09- \\
3.34)\end{array}$ & 0.523 & $0.5(4)$ & $1.9(16)$ & $\begin{array}{l}0.26(0.09- \\
0.77)\end{array}$ & 0.015 & 0.466 \\
\hline Any MI & $3.6(3)$ & $5.7(4)$ & $\begin{array}{l}0.62(0.14- \\
2.78)\end{array}$ & 0.534 & $2.2(18)$ & $3.6(30)$ & $\begin{array}{l}0.61(0.34- \\
1.1)\end{array}$ & 0.102 & 0.994 \\
\hline Any stroke & $0(0)$ & $0(0)$ & $0(0-0)$ & & $1.4(11)$ & $0.1(1)$ & $\begin{array}{l}11.35(1.47- \\
87.95)\end{array}$ & 0.020 & 0.998 \\
\hline $\begin{array}{l}\text { Any repeat } \\
\text { revasculari- } \\
\text { zation }\end{array}$ & $1.2(1)$ & $2.8(2)$ & $\begin{array}{l}0.42(0.04- \\
4.63)\end{array}$ & 0.478 & $1.4(11)$ & $3.1(26)$ & $\begin{array}{l}0.43(0.21- \\
0.87)\end{array}$ & 0.020 & 0.977 \\
\hline \multicolumn{10}{|l|}{ At 5 years } \\
\hline MACCE & $35.9(28)$ & $47.3(33)$ & $\begin{array}{l}0.73(0.44- \\
1.2)\end{array}$ & 0.213 & $27.1(201)$ & 36.8 (299) & $\begin{array}{l}0.67(0.56- \\
0.8)\end{array}$ & $<0.001$ & 0.805 \\
\hline $\begin{array}{l}\text { All-cause } \\
\text { death, } \\
\text { stroke, MI }\end{array}$ & $28.3(22)$ & $31.5(22)$ & $0.9(0.5-1.63)$ & 0.729 & $16.6(121)$ & $19.9(163)$ & $\begin{array}{c}0.78(0.62- \\
0.99)\end{array}$ & 0.038 & 0.677 \\
\hline $\begin{array}{l}\text { All-cause } \\
\text { death }\end{array}$ & $23.3(18)$ & $23.1(16)$ & $\begin{array}{l}1.01(0.52- \\
1.99)\end{array}$ & 0.969 & $11.2(79)$ & 13.1 (107) & $\begin{array}{l}0.78(0.58- \\
1.04)\end{array}$ & 0.092 & 0.475 \\
\hline Cardiac death & $11.7(9)$ & $16.1(11)$ & $\begin{array}{l}0.73(0.3- \\
1.76)\end{array}$ & 0.483 & $5.0(35)$ & $8.4(67)$ & $\begin{array}{l}0.55(0.37- \\
0.83)\end{array}$ & 0.004 & 0.563 \\
\hline Any MI & $4.9(4)$ & $15.3(10)$ & $\begin{array}{l}0.35(0.11- \\
1.11)\end{array}$ & 0.073 & 3.7 (29) & $9.2(73)$ & $\begin{array}{l}0.41(0.27- \\
0.63)\end{array}$ & $<0.001$ & 0.782 \\
\hline Any stroke & $5.6(4)$ & $3.1(2)$ & $\begin{array}{l}1.84(0.34- \\
10.04)\end{array}$ & 0.482 & $3.6(27)$ & $2.3(18)$ & $1.6(0.88-2.9)$ & 0.125 & 0.888 \\
\hline $\begin{array}{l}\text { Any repeat } \\
\text { revasculari- } \\
\text { zation }\end{array}$ & $12.9(9)$ & $31.9(20)$ & $\begin{array}{l}0.38(0.17- \\
0.84)\end{array}$ & 0.016 & $13.8(101)$ & $26.3(202)$ & $\begin{array}{l}0.49(0.39- \\
0.63)\end{array}$ & $<0.001$ & 0.532 \\
\hline \multicolumn{10}{|l|}{ At 10 years } \\
\hline $\begin{array}{l}\text { All-cause } \\
\text { death }\end{array}$ & $42.3(34)$ & $43.9(30)$ & $\begin{array}{l}0.96(0.59- \\
1.56)\end{array}$ & 0.858 & 22.7 (178) & $27.1(218)$ & $\begin{array}{l}0.81(0.67- \\
0.99)\end{array}$ & 0.041 & 0.554 \\
\hline
\end{tabular}

$C O P D$ chronic obstructive pulmonary disease, $M I$ myocardial infarction, MACCE major adverse cardiovascular and cerebrovascular event. Data are presented as percentage based on Kaplan-Meier estimates (number of deaths)

similar morbidity and mortality rates among the patients with and without COPD who underwent off-pump CABG [31]. Based on this evidence, CABG should be considered as an alternative revascularization strategy for patients with COPD. However, further large-scale studies are needed.

\section{COPD was an independent predictor of 10-year all-cause mortality after CABG but not after PCI}

Previous studies had demonstrated that COPD was a predictor of long-term mortality after CABG [10]. A single-center analysis with a total of 10,994 patients found that COPD was a significant independent predictor of in-hospital death and long-term mortality after PCI [16], whereas another study reported that COPD was not an independent predictor of major adverse clinical outcomes in patients with STEMI following PCI [32]. In the SYNTAX trial, COPD was independently associated with 4-year mortality after CABG but not after PCI $[4,33]$. Similarly, in SYNTAXES, with a follow-up out to 10 years, we found COPD was an independent predictor in the CABG arm but not in the PCI arm in the SYNTAXES. Therefore, COPD remains as one 

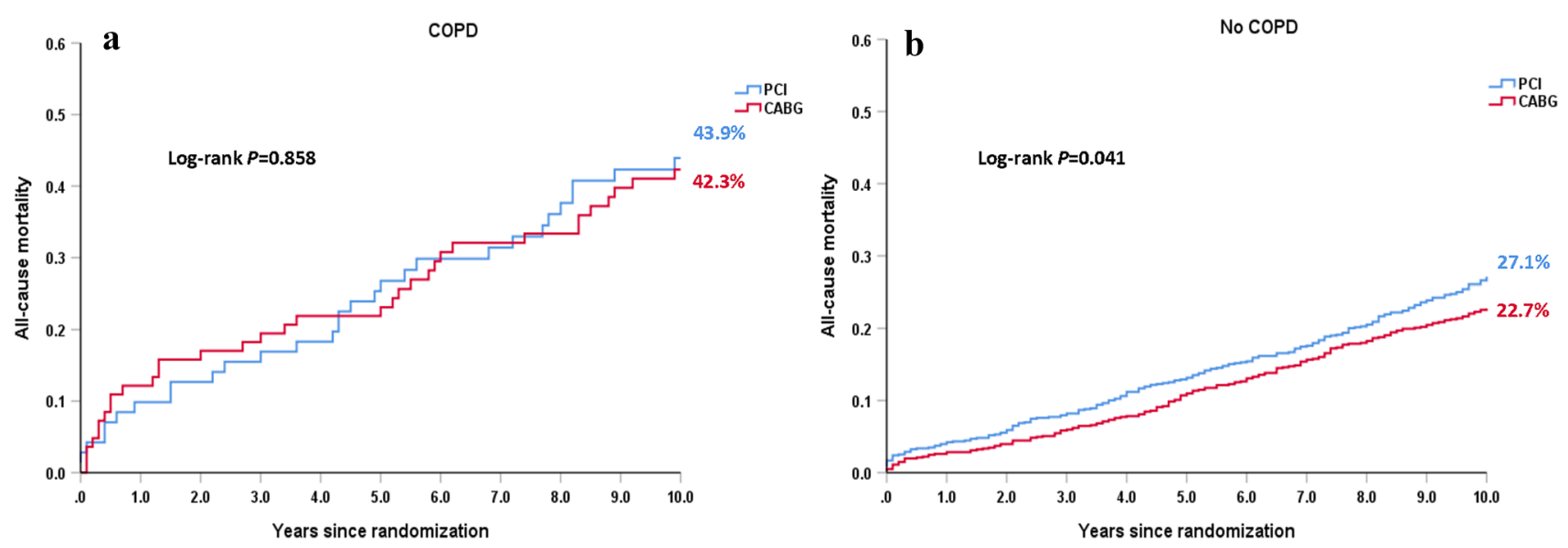

Fig. 2 Kaplan-Meier curves for all-cause death at 10 years in patients randomized to PCI (blue) vs. CABG (red) among patients with and without COPD. a All-cause mortality at 10 years in patients with

COPD. b All-cause mortality at 10 years in patients without COPD. Event rates represent Kaplan-Meier estimates

Table 5 The association between COPD and 10-year all-cause mortality

\begin{tabular}{|c|c|c|c|c|c|c|}
\hline & \multicolumn{2}{|l|}{ Overall population } & \multicolumn{2}{|l|}{ PCI arm } & \multicolumn{2}{|l|}{ CABG arm } \\
\hline & $\begin{array}{l}\text { Adjusted } \\
\text { HR }(95 \% \text { CI) }\end{array}$ & $p$ & $\begin{array}{l}\text { Adjusted } \\
\text { HR }(95 \% \text { CI })\end{array}$ & $p$ & $\begin{array}{l}\text { Adjusted } \\
\text { HR }(95 \% \text { CI })\end{array}$ & $p$ \\
\hline PVD & $2.33(1.71-3.17)$ & $<0.001$ & $2.61(1.64-4.16)$ & $<0.001$ & $2.28(1.48-3.51)$ & $<0.001$ \\
\hline Current smoking & $2.17(1.59-2.97)$ & $<0.001$ & $2.44(1.60-3.73)$ & $<0.001$ & $2.05(1.28-3.30)$ & 0.003 \\
\hline Age (per 10 years increase) & $2.02(1.67-2.43)$ & $<0.001$ & $1.65(1.29-2.11)$ & $<0.001$ & $2.72(2.01-3.69)$ & $<0.001$ \\
\hline Previous stroke & $1.72(1.05-2.83)$ & 0.033 & $1.20(0.55-2.59)$ & 0.645 & $2.33(1.19-4.57)$ & 0.014 \\
\hline Pharmacologically-treated diabetes & $1.63(1.25-2.12)$ & $<0.001$ & $1.66(1.16-2.38)$ & 0.006 & $1.68(1.14-2.49)$ & 0.010 \\
\hline COPD & $1.50(1.01-2.20)$ & 0.042 & $1.19(0.69-2.06)$ & 0.536 & $2.10(1.19-3.69)$ & 0.010 \\
\hline LVEF (per 10\% decrease) & $1.14(1.03-1.25)$ & 0.011 & $1.18(1.02-1.33)$ & 0.020 & $1.11(0.96-1.28)$ & 0.165 \\
\hline Previous MI & $1.12(0.86-1.47)$ & 0.403 & $1.10(0.76-1.59)$ & 0.619 & $1.05(0.69-1.61)$ & 0.812 \\
\hline Anatomical SYNTAX score (per 10 point increase) & $1.10(0.99-1.21)$ & 0.076 & $1.18(1.03-1.35)$ & 0.014 & $0.99(0.84-1.16)$ & 0.887 \\
\hline Female & $1.04(0.78-1.38)$ & 0.795 & $1.07(0.73-1.57)$ & 0.740 & $0.97(0.63-1.49)$ & 0.882 \\
\hline Creatinine clearance (per 10 ml/min decrease) & $1.03(0.97-1.10)$ & 0.273 & $1.09(1.00-1.18)$ & 0.055 & $0.97(0.88-1.08)$ & 0.567 \\
\hline Body mass index (per unit increase) & $1.02(0.99-1.05)$ & 0.275 & $1.02(0.98-1.06)$ & 0.365 & $1.00(0.95-1.05)$ & 0.964 \\
\hline
\end{tabular}

$C O P D$ chronic obstructive pulmonary disease, $L V E F$ left ventricular ejection fraction, $M I$ myocardial infarction, $P V D$ peripheral vascular disease

of the prognostic indexes in the SYNTAX score II 2020 [9]. COPD was a significant risk factor for non-adherence to medications, such as beta blockers, and underutilization of beta blockers in COPD was associated with clinicians concerns about bronchoconstriction [34]. In the SYNTAX study, patients with COPD were less likely to receive aspirin and beta blockers at discharge. However, after adjustment for the prescriptions of aspirin and beta blockers at discharge, COPD remains an independent predictor of 10-year all-cause death (HR: 1.52, 95\% CI: 1.03-2.24, $p=0.037$ in overall population, HR: 2.19, 95\% CI: $1.24-3.89, p=0.007$ in CABG arm). Patients with COPD represent a high-risk cohort where adherence to treatment guidelines is crucial.
Clinicians should take particular care with respect to the use of beta blockers and aspirin in patients with COPD, since prior studies demonstrated that both beta blockers and aspirin are not only safe but could also reduce all-cause death in patients with COPD $[35,36]$. The majority of the studies in the field demonstrated that patients with a history of COPD have higher mortality rates than those without COPD, either after PCI or CABG. Therefore, in clinical practice, we should pay more attention to patients with COPD and use multidisciplinary care and self-management [37], a double health care approach that might improve the outcomes post revascularization no matter what modality of revascularization is used. 


\section{Limitations}

Several limitations should be considered in our current study. First, due to the modest sample size, the present analyses might not have adequate statistical power. Further largescale trials more specifically dedicated to COPD patients are warranted. Second, this is a post hoc analysis and should be interpreted as hypothesis-generating only [38]. Third, the SYNTAX trial enrolled patients with de novo 3VD and/ or LMCAD, and the findings should not be extrapolated to other CAD patients. COPD at baseline was defined according to the definition in EuroSCORE which is not specific for COPD; that definition does not differentiate asthma from COPD patients. However, it has been demonstrated in prior studies that asthma, as comorbidity, is independently associated with ischemic heart disease to an extent similar as COPD [39]. Another major limitation is that in the SYNTAXES study, the severity of COPD, emphysema, GOLD groups or grades, COPD exacerbations, pulmonary function tests (such as FEV1), and the use of long-term oxygen therapy or noninvasive ventilation were not available. Moreover, the endpoint in the SYNTAXES study was solely 10-year all-cause death. However, the SYNTAXES study provided data from the first randomized trial, comparing surgery and PCI with drug eluting stent, for which 10-year vital status was available in $93.8 \%$ of the patients. It has to be acknowledged that the PCI patients were treated with a first-generation drug eluting stent, which is no longer commercially available. Nevertheless, it is inevitable that any long-term observational data will be derived from a population treated with outdated/obsolete technology, while the evidence provided by contemporary technology can be derived only from short-term follow-up studies. Finally, an inherent bias may exist that patients with severe COPD who were deemed extremely high risk for CABG may not have been included in the randomized cohort and directed to the PCI registry in the SYNTAX trial.

\section{Conclusions}

In the SYNTAXES trial, COPD was associated with a higher risk of 10-year all-cause death in patients with $3 \mathrm{VD}$ and/or LMCAD following either PCI or CABG. The risk of allcause death at 10 years in patients with CABG versus PCI was similar irrespective of the prevalence of COPD.

Funding The SYNTAX Extended Survival study was supported by the German Foundation of Heart Research (Frankfurt am Main, Germany). The SYNTAX trial, during 0-5 year follow-up, was funded by Boston Scientific Corporation (Marlborough, MA, USA). Both sponsors had no role in the study design, data collection, data analyses and interpretation of the study data, nor were involved in the decision to publish the final manuscript. The principal investigators and authors had complete scientific freedom.

\section{Declarations}

Conflict of interest Dr. Serruys reports personal fees from Biosensors, Micel Technologies, Sinomedical Sciences Technology, Philips/ Volcano, Xeltis, and HeartFlow, outside the submitted work. Dr. van Geuns reports personal fees from Abbott vascular, grants and personal fees from AstraZeneca, grants and personal fees from Amgen, grants and personal fees from Boston Scientific, personal fees from Sanofi, outside the submitted work. Dr. Morice reports to work as the CEO of CERC, a CRO which was never involved in the SYNTAX trial at any level, except that submitted the 10 years additional follow-up (for free) to French authorities to get approval. Dr. Morice also reports to work as minor shareholder of electroducer. Dr. Burzotta reports speaker's fees from Abiomed, Abbott and Medtronic. Dr. Kappetein reports to work as an employee of Medtronic, outside the submitted work. Dr. James's institution has received research grants from Boston Sc, Abbot, Biotronik, Medtronic, Astra Zeneca, Bayer, Jansen, The MedCo, and has received lecture fees from Biotronik, Astra Zeneca. All other authors have no disclosures.

Open Access This article is licensed under a Creative Commons Attribution 4.0 International License, which permits use, sharing, adaptation, distribution and reproduction in any medium or format, as long as you give appropriate credit to the original author(s) and the source, provide a link to the Creative Commons licence, and indicate if changes were made. The images or other third party material in this article are included in the article's Creative Commons licence, unless indicated otherwise in a credit line to the material. If material is not included in the article's Creative Commons licence and your intended use is not permitted by statutory regulation or exceeds the permitted use, you will need to obtain permission directly from the copyright holder. To view a copy of this licence, visit http://creativecommons.org/licenses/by/4.0/.

\section{References}

1. Rabe KF, Hurst JR, Suissa S (2018) Cardiovascular disease and COPD: dangerous liaisons? Eur Respir Rev. https://doi.org/10. 1183/16000617.0057-2018

2. Andre S, Conde B, Fragoso E et al (2019) COPD and cardiovascular disease. Pulmonology 25(3):168-176. https://doi.org/10. 1016/j.pulmoe.2018.09.006

3. Sin DD, Man SF (2005) Chronic obstructive pulmonary disease as a risk factor for cardiovascular morbidity and mortality. Proc Am Thorac Soc 2(1):8-11. https://doi.org/10.1513/pats. 200404-032MS

4. Farooq V, van Klaveren D, Steyerberg EW et al (2013) Anatomical and clinical characteristics to guide decision making between coronary artery bypass surgery and percutaneous coronary intervention for individual patients: development and validation of SYNTAX score II. Lancet 381(9867):639-650. https://doi.org/ 10.1016/s0140-6736(13)60108-7

5. Serruys PWCP, Modolo R et al (2020) The SYNTAX score on its way out or ... towards artificial intelligence: part I. EuroIntervention 16(1):44-59. https://doi.org/10.4244/EIJ-D-17-00355

6. Serruys PWCP, Modolo R et al (2020) The SYNTAX score on its way out or ... towards artificial intelligence: part II. EuroIntervention 16(5):60-75

7. Shahian DM, O'Brien SM, Filardo G et al (2009) The Society of Thoracic Surgeons 2008 cardiac surgery risk models: part 
1-coronary artery bypass grafting surgery. Ann Thorac Surg 88(1 Suppl):S2-22. https://doi.org/10.1016/j.athoracsur.2009.05.053

8. Nashef SA, Roques F, Sharples LD et al (2012) EuroSCORE II. Eur J Cardiothorac Surg. 41(4):734-44; discussion 44-5. https:// doi.org/10.1093/ejcts/ezs043

9. Takahashi K, Serruys PW, Fuster V et al (2020) Redevelopment and validation of the SYNTAX score II to individualise decision making between percutaneous and surgical revascularisation in patients with complex coronary artery disease: secondary analysis of the multicentre randomised controlled SYNTAXES trial with external cohort validation. Lancet 396(10260):1399-1412. https:// doi.org/10.1016/s0140-6736(20)32114-0

10. Leavitt BJ, Ross CS, Spence B et al (2006) Long-term survival of patients with chronic obstructive pulmonary disease undergoing coronary artery bypass surgery. Circulation 114(1 Suppl):I430 I434. https://doi.org/10.1161/CIRCULATIONAHA.105.000943

11. O'Boyle F, Mediratta N, Chalmers J et al (2013) Long-term survival of patients with pulmonary disease undergoing coronary artery bypass surgery. Eur J Cardiothorac Surg 43(4):697-703. https://doi.org/10.1093/ejcts/ezs454

12. Manganas H, Yves L, Bourgeois S, Perron J, Dagenais F, Maltais F (2007) Postoperative outcome after coronary artery bypass grafting in chronic obstructive pulmonary disease. Can Respir J. 14(1):19-24

13. Zhao H, Li L, Yang G et al (2019) Postoperative outcomes of patients with chronic obstructive pulmonary disease undergoing coronary artery bypass grafting surgery: a meta-analysis. Medicine (Baltimore) 98(6):e14388. https://doi.org/10.1097/MD.00000 00000014388

14. Bundhun PK, Gupta C, Xu GM (2017) Major adverse cardiac events and mortality in chronic obstructive pulmonary disease following percutaneous coronary intervention: a systematic review and meta-analysis. BMC Cardiovasc Disord 17(1):191. https://doi. org/10.1186/s12872-017-0622-2

15. Andell P, Sjogren J, Batra G, Szummer K, Koul S (2017) Outcome of patients with chronic obstructive pulmonary disease and severe coronary artery disease who had a coronary artery bypass graft or a percutaneous coronary intervention. Eur J Cardiothorac Surg 52(5):930-936. https://doi.org/10.1093/ejcts/ezx219

16. Selvaraj CL, Gurm HS, Gupta R, Ellis SG, Bhatt DL (2005) Chronic obstructive pulmonary disease as a predictor of mortality in patients undergoing percutaneous coronary intervention. Am J Cardiol 96(6):756-759. https://doi.org/10.1016/j.amjcard. 2005.05.016

17. Tomaniak M, Chichareon P, Takahashi K et al (2019) Impact of chronic obstructive pulmonary disease and dyspnoea on clinical outcomes in ticagrelor treated patients undergoing percutaneous coronary intervention in the randomized GLOBAL LEADERS trial. Eur Heart J Cardiovasc Pharmacother. https://doi.org/10. 1093/ehjcvp/pvz052

18. Huang X, Redfors B, Chen S et al (2019) Impact of chronic obstructive pulmonary disease on prognosis after percutaneous coronary intervention and bypass surgery for left main coronary artery disease: an analysis from the EXCEL trial. Eur J Cardiothorac Surg 55(6):1144-1151. https://doi.org/10.1093/ejcts/ ezy438

19. Thuijs DJFM, Kappetein AP, Serruys PW et al (2019) Percutaneous coronary intervention versus coronary artery bypass grafting in patients with three-vessel or left main coronary artery disease: 10-year follow-up of the multicentre randomised controlled SYNTAX trial. Lancet 394(10206):1325-1334. https://doi.org/10. 1016/s0140-6736(19)31997-x

20. Ong AT, Serruys PW, Mohr FW et al (2006) The SYNergy between percutaneous coronary intervention with TAXus and cardiac surgery (SYNTAX) study: design, rationale, and run-in phase. Am Heart J 151(6):1194-1204. https://doi.org/10.1016/j. ahj.2005.07.017

21. Serruys PWMM, Kappetein AP, Colombo A, Holmes DR, Mack MJ, Stahle E, Feldman TE, van den Brand M, Bass EJ, Van Dyck N, Leadley K, Dawkins KD, Mohr FW, Investigators S (2009) Percutaneous coronary intervention versus coronary-artery bypass grafting for severe coronary artery disease. N Engl J Med 360:961-972

22. Mohr FW, Morice M-C, Kappetein AP et al (2013) Coronary artery bypass graft surgery versus percutaneous coronary intervention in patients with three-vessel disease and left main coronary disease: 5-year follow-up of the randomised, clinical SYNTAX trial. Lancet 381(9867):629-638. https://doi.org/10.1016/ s0140-6736(13)60141-5

23. Nashef SARF, Michel P, Gauducheau E, Lemeshow S, Salamon R (1999) European system for cardiac operative risk evaluation (EuroSCORE). Eur J Cardiothorac Surg 16:9-13

24. Pocock SJ, McMurray JJV, Collier TJ (2015) Statistical controversies in reporting of clinical trials: Part 2 of a 4-part series on statistics for clinical trials. J Am Coll Cardiol 66(23):2648-2662. https://doi.org/10.1016/j.jacc.2015.10.023

25. Sin DD, Man SF (2003) Why are patients with chronic obstructive pulmonary disease at increased risk of cardiovascular diseases? The potential role of systemic inflammation in chronic obstructive pulmonary disease. Circulation 107(11):1514-1519. https://doi. org/10.1161/01.cir.0000056767.69054.b3

26. Angouras DC, Anagnostopoulos CE, Chamogeorgakis TP et al (2010) Postoperative and long-term outcome of patients with chronic obstructive pulmonary disease undergoing coronary artery bypass grafting. Ann Thorac Surg 89(4):1112-1118. https://doi. org/10.1016/j.athoracsur.2010.01.009

27. Berger JS, Sanborn TA, Sherman W, Brown DL (2004) Effect of chronic obstructive pulmonary disease on survival of patients with coronary heart disease having percutaneous coronary intervention. Am J Cardiol 94(5):649-651. https://doi.org/10.1016/j.amjcard. 2004.05.034

28. Samuels LE, Kaufman MS, Morris RJ, Promisloff R, Brockman SK (1998) Coronary artery bypass grafting in patients with COPD. Chest 113(4):878-882. https://doi.org/10.1378/chest. 113.4.878

29. Fuster RG, Argudo JA, Albarova OG et al (2006) Prognostic value of chronic obstructive pulmonary disease in coronary artery bypass grafting. Eur J Cardiothorac Surg 29(2):202-209. https:// doi.org/10.1016/j.ejcts.2005.11.015

30. Michalopoulos A, Geroulanos S, Papadimitriou L et al (2001) Mild or moderate chronic obstructive pulmonary disease risk in elective coronary artery bypass grafting surgery. World J Surg 25(12):1507-1511. https://doi.org/10.1007/s00268-001-0161-x

31. Ovali C, Sahin A (2018) Chronic obstructive pulmonary disease and off-pump coronary surgery. Ann Thorac Cardiovasc Surg 24(4):193-199. https://doi.org/10.5761/atcs.oa.17-00231

32. Sung PH, Chung SY, Sun CK et al (2013) Impact of chronic obstructive pulmonary disease on patient with acute myocardial infarction undergoing primary percutaneous coronary intervention. Biomed J 36(6):274-281. https://doi.org/10.4103/2319-4170. 113373

33. Farooq V, Serruys PW, Bourantas C et al (2012) Incidence and multivariable correlates of long-term mortality in patients treated with surgical or percutaneous revascularization in the synergy between percutaneous coronary intervention with taxus and cardiac surgery (SYNTAX) trial. Eur Heart J 33(24):3105-3113. https://doi.org/10.1093/eurheartj/ehs367

34. Rasmussen DB, Bodtger U, Lamberts M et al (2020) Beta-blocker, aspirin, and statin usage after first-time myocardial infarction in patients with chronic obstructive pulmonary disease: a nationwide 
analysis from 1995 to 2015 in Denmark. Eur Heart J Qual Care Clin Outcomes 6(1):23-31. https://doi.org/10.1093/ehjqcco/ qcy063

35. Yang YL, Xiang ZJ, Yang JH, Wang WJ, Xu ZC, Xiang RL (2020) Association of beta-blocker use with survival and pulmonary function in patients with chronic obstructive pulmonary and cardiovascular disease: a systematic review and meta-analysis. Eur Heart J 41(46):4415-4422. https://doi.org/10.1093/eurheartj/ ehaa793

36. Goto T, Faridi MK, Camargo CA, Hasegawa K (2018) The association of aspirin use with severity of acute exacerbation of chronic obstructive pulmonary disease: a retrospective cohort study. NPJ Prim Care Respir Med 28(1):7. https://doi.org/10.1038/ s41533-018-0074-x

37. Marlies Zwerink MBK, van der Valk PDLPM, Zielhuis GA, Monninkhof EM, van der Palen J, Frith PA, Effing T (2014) Self management for patients with chronic obstructive pulmonary disease. Cochrane Database Syst Rev. 3:CD002990

38. Milojevic M, Nikolic A, Juni P, Head SJ (2020) A statistical primer on subgroup analyses. Interact Cardiovasc Thorac Surg. https://doi.org/10.1093/icvts/ivaa042

39. Carter P, Lagan J, Fortune C et al (2019) Association of cardiovascular disease with respiratory disease. J Am Coll Cardiol 73(17):2166-2177. https://doi.org/10.1016/j.jacc.2018.11.063 